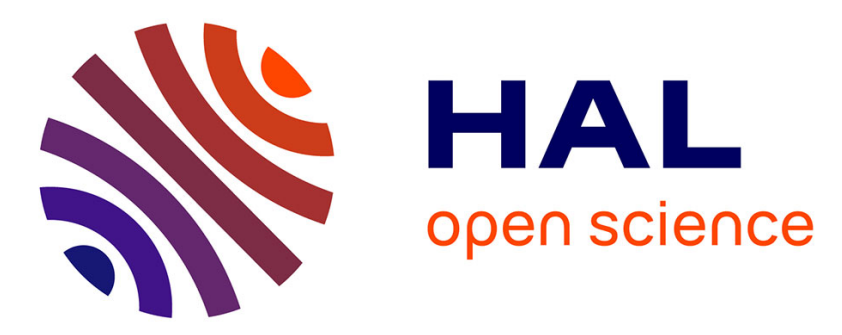

\title{
Generally weighted moving average monitoring schemes: Overview and perspectives
}

\author{
Kutele Mabude, Jean-claude Malela-majika, Philippe Castagliola, Sandile \\ Shongwe
}

\section{- To cite this version:}

Kutele Mabude, Jean-claude Malela-majika, Philippe Castagliola, Sandile Shongwe. Generally weighted moving average monitoring schemes: Overview and perspectives. Quality and Reliability Engineering International, 2021, 37 (2), pp.409-432. 10.1002/qre.2765 . hal-03321174

\section{HAL Id: hal-03321174 \\ https://hal.science/hal-03321174}

Submitted on 17 Aug 2021

HAL is a multi-disciplinary open access archive for the deposit and dissemination of scientific research documents, whether they are published or not. The documents may come from teaching and research institutions in France or abroad, or from public or private research centers.
L'archive ouverte pluridisciplinaire HAL, est destinée au dépôt et à la diffusion de documents scientifiques de niveau recherche, publiés ou non, émanant des établissements d'enseignement et de recherche français ou étrangers, des laboratoires publics ou privés. 


\title{
Generally Weighted Moving Average monitoring schemes - Overview and Perspectives
}

\author{
${ }^{1}$ Mabude K., ${ }^{1}$ Malela-Majika J.-C., ${ }^{2}$ Castagliola P. and ${ }^{1 *}$ Shongwe S.C.
}

\begin{abstract}
An overview of monitoring schemes from a class called generally weighted moving average (GWMA) is provided. A GWMA scheme is an extended version of the exponentially weighted moving average (EWMA) scheme with an additional adjustment parameter that introduces more flexibility in the GWMA model as it adjusts the kurtosis of the weighting function so that the GWMA scheme can be designed such that it has an advantage over the corresponding EWMA scheme in the detection of certain shift values efficiently. The parametric and distribution-free GWMA schemes to monitor various quality characteristics and its existing enhanced versions (i.e. double GWMA, composite Shewhart-GWMA, mixed GWMA-CUSUM and mixed CUSUM-GWMA) have better performance than their corresponding EWMA counterparts in many situations; hence, all such existing research works discussing GWMA-related schemes (i.e. 61 publications in total) are documented and categorized in such a manner that it is easy to identify research gaps. Finally, a number of possible future research ideas are provided.
\end{abstract}

Keywords: Generally weighted moving average, GWMA, Memory-type scheme, Run-length, Monte Carlo Simulation.

\section{Introduction}

In any field, a literature review is essential as it gives an overview of what investigations have been conducted and what are some of the possible research ideas that can be pursued. In statistical process monitoring (SPM) there have been a number of literature reviews that have shed some light on the current state of a particular topic and in doing so, made way for many publications thereafter; see for instance ${ }^{1,2,3,4,5}$. Thus, the tradition emphasized by the latter articles is continued with the generally weighted moving average (GWMA) monitoring schemes in this paper. The exponentially weighted moving average (EWMA) monitoring scheme with an additional adjustment parameter was discussed in Sheu and Griffith ${ }^{6}$, Sheu ${ }^{7,8}$ as an enhancement procedure to further improve the sensitivity of the EWMA scheme towards small shifts in the process mean. Thereafter, Sheu and Lin $^{9}$ formally introduced this enhancement procedure as a stand-alone monitoring scheme which is simply called the GWMA control chart; and they defined it as a moving average of past data where a specific weight is assigned to each data point. Moreover, the moving average tends to be a representation of the more recent process performance, as larger weights are allocated to the most recent observations. In addition, Sheu and $\operatorname{Lin}^{9}$ derived the properties that are required to compute the run-length distribution and they discussed its importance as well as illustrated its implementation.

The purpose of this literature review is to acquaint SPM researchers as well as practitioners about GWMA schemes which were supposed to be, in essence, replacements of the EWMA-type schemes; however, this is not really the case in the literature or in practice; because there are actually way more

\footnotetext{
${ }^{*}$ Corresponding author. S.C. Shongwe. E-mail: sandile@tuks.co.za.

${ }^{1}$ Department of Statistics, College of Science, Engineering and Technology, University of South Africa; Pretoria, South Africa; ${ }^{2}$ Département Qualité Logistique Industrielle et Organisation, Université de Nantes \& LS2N UMR CNRS 6004, Nantes, France.
} 
research output that have been reported on EWMA schemes than on the GWMA schemes from 2003 to mid-year 2020. Based on different authors who have commented on the latter predicament, they have indicated that the implementation of the EWMA scheme is easier as compared to that of the GWMA one. By conducting this review, it is also meant to convince researchers and practitioners alike that GWMA schemes are not as complex as they are thought to be and to further explain that they provide fascinating results when compared to other well-known monitoring schemes, more especially, the EWMA monitoring scheme.

Since 2003, the year of publication of the first article, there have been a total of 61 publications on the GWMA-related monitoring schemes and their enhancements. So far, the existing known enhancements of the GWMA-related scheme are:

- the double GWMA scheme - denoted as DGWMA scheme;

- the composite Shewhart-GWMA scheme;

- the mixed GWMA-CUSUM scheme and its reverse version, the mixed CUSUM-GWMA scheme.

A DGWMA scheme is a weighted moving average of a weighted moving average; which implies that the smoothing process is done twice (this concept was first introduced by Shamma and Shamma ${ }^{10}$ for the double EWMA (DEWMA) scheme). A composite Shewhart-GWMA scheme is a combination of the Shewhart and GWMA schemes which is an efficient way of harnessing the benefits of these two schemes (this concept was first introduced by Lucas ${ }^{11}$ and Lucas and Saccucci ${ }^{12}$ for the ShewhartCUSUM and Shewhart-EWMA schemes, respectively). The mixed GWMA-CUSUM scheme is a combination of the GWMA and CUSUM schemes where the GWMA statistic is used as input in the CUSUM scheme; however, the CUSUM-GWMA scheme uses the CUSUM statistic as input in the GWMA scheme (this concept was first introduced by Abbas et $\mathrm{al}^{13}$ for the EWMA-CUSUM scheme and the reverse version was introduced by Zaman et $\mathrm{al}^{14}$ ).

The basic properties of the GWMA scheme and its existing enhancements as well as a detailed outline of how the review is structured are provided in Section 2. Thereafter, the publications discussing research works on GWMA, DGWMA, Shewhart-GWMA and GWMA-CUSUM (as well as its reverse version) schemes are reviewed in Sections 3, 4, 5 and 6, respectively. Section 7 provides concluding remarks and some possible future research ideas. Finally, Appendices A and B provide an illustration of how the weight function kurtosis varies for different design parameters and an outline of how the run-length properties are determined for GWMA-related monitoring schemes, respectively. 


\section{Basic propeties of GWMA schemes and their enhancements}

\subsection{Operation of the GWMA scheme and its enhancements}

The weight structure of the GWMA $\bar{X}$ scheme as compared to the corresponding EWMA scheme for various design parameters are discussed in Appendix A. Assume that the quality characteristic of interest is a subgroup mean, then $\bar{X}_{t}$ are i.i.d. (independent and identically distributed) normally distributed random variables with in-control (IC) mean $\mu_{0}$ and standard deviation $\frac{\sigma_{0}}{\sqrt{n}}$. In this section, the operation of the GWMA scheme and its enhancements are illustrated for the subgroup mean. The charting statistic of the GWMA $\bar{X}$ scheme is given by

$$
\begin{aligned}
G_{t} & =P\left(M_{1}=1\right) \bar{X}_{t}+P\left(M_{1}=2\right) \bar{X}_{t-1}+\cdots+P\left(M_{1}=t\right) \bar{X}_{1}+P\left(M_{1}>t\right) \mu_{0} \\
& =\left(q_{1}^{0^{\alpha_{1}}}-q_{1}^{1^{\alpha_{1}}}\right) \bar{X}_{t}+\left(q_{1}^{1^{\alpha_{1}}}-q_{1}^{2^{\alpha_{1}}}\right) \bar{X}_{t-1}+\cdots+\left(q_{1}^{(t-1)^{\alpha_{1}}}-q_{1}^{t^{\alpha_{1}}}\right) \bar{X}_{1}+q_{1}^{t^{\alpha_{1}}} \mu_{0} \\
& =\sum_{i=1}^{t}\left(q_{1}^{(i-1)^{\alpha_{1}}}-q_{1}^{i^{\alpha_{1}}}\right) \bar{X}_{t-i+1}+q_{1}^{t^{\alpha_{1}}} \mu_{0} ;
\end{aligned}
$$

where $M_{1}$ is defined in Appendix A, $0<q_{1} \leq 1$ and $\alpha_{1}>0$. The expected value and standard deviation of $G_{t}$ are given by

$$
E\left(G_{t}\right)=\mu_{0} \text { and } \sigma\left(G_{t}\right)=\frac{\sigma_{0}}{\sqrt{n}} \sqrt{Q_{t}}
$$

where

$$
Q_{t}=\sum_{i=1}^{t}\left(q_{1}^{(i-1)^{\alpha_{1}}}-q_{1}^{i^{\alpha_{1}}}\right)^{2} .
$$

Hence, the time-varying upper and lower control limits (denoted as $U C L_{G_{t}}$ and $L C L_{G_{t}}$ ) of the GWMA $\bar{X}$ monitoring scheme are calculated as (with $L_{G}>0$, i.e. a width parameter):

$$
U C L_{G_{t}} / L C L_{G_{t}}=E\left(G_{t}\right) \pm L_{G} \sigma\left(G_{t}\right) .
$$

When $t \rightarrow \infty$, Equation (3) reduces to the following limiting constant

$$
Q=\lim _{t \rightarrow \infty}\left(\sum_{i=1}^{t}\left(q_{1}^{(i-1)^{\alpha_{1}}}-q_{1}^{i^{\alpha_{1}}}\right)^{2}\right) .
$$

Thus, the asymptotic upper and lower control limits (denoted as $U C L_{G}$ and $L C L_{G}$ ):

$$
U C L_{G} / L C L_{G}=\mu_{0} \pm L_{G} \frac{\sigma_{0}}{\sqrt{n}} \sqrt{Q}
$$

The above derivations given in Equations (1) to (5) are summarized in Table 1. Following a similar line of argument, it follows that the charting statistics, design parameters and control limits of the DGWMA, Shewhart-GWMA, GWMA-CUSUM and CUSUM-GWMA $\bar{X}$ schemes are as shown in Table 1. For more details on the properties summarized in Table 1, refer to Sheu and $\operatorname{Lin}^{9}, \operatorname{Lin}^{15}, \mathrm{Lu}^{16}$ and, Ali and $\mathrm{Haq}^{17}$. 
Table 1: An illustration of different charting statistics, design parameters and control limits of the GWMA scheme and its existing enhancements when the characteristic of interest is the process mean

\begin{tabular}{|c|c|c|c|c|}
\hline Scheme & Charting statistics & $\begin{array}{c}\text { Design } \\
\text { parameters }\end{array}$ & $\begin{array}{l}\text { Time-varying } \\
\text { control limits }\end{array}$ & $\begin{array}{c}\text { Asymptotic } \\
\text { control limits }\end{array}$ \\
\hline GWMA & $G_{t}=\sum_{i=1}^{t}\left(q_{1}^{(i-1)^{\alpha_{1}}}-q_{1}^{i^{\alpha_{1}}}\right) \bar{X}_{t-i+1}+q_{1}^{t^{\alpha_{1}}} \mu_{0}$ & $\begin{aligned} L_{G}>0 \\
0<q_{1} \leq 1 \\
\quad \alpha_{1}>0\end{aligned}$ & $\begin{array}{l}U C L_{G_{t}} / L C L_{G_{t}}=\mu_{0} \pm L_{G} \frac{\sigma_{0}}{\sqrt{n}} \sqrt{Q_{t}} \\
\text { with } \\
\qquad Q_{t}=\sum_{i=1}^{t}\left(q_{1}^{(i-1)^{\alpha_{1}}}-q_{1}^{i^{\alpha_{1}}}\right)^{2}\end{array}$ & $\begin{array}{l}U C L_{G} / L C L_{G}=\mu_{0} \pm L_{G} \frac{\sigma_{0}}{\sqrt{n}} \sqrt{Q} \\
\text { with } \\
Q=\lim _{t \rightarrow \infty}\left(\sum_{i=1}^{t}\left(q_{1}^{(i-1)^{\alpha_{1}}}-q_{1}^{i^{\alpha_{1}}}\right)^{2}\right)\end{array}$ \\
\hline DGWMA & $\begin{array}{c}\qquad D G_{t}=\sum_{i=1}^{t} W_{i} \bar{X}_{t-i+1}+\left(1-\sum_{i=1}^{t} W_{i}\right) \mu_{0} \\
\text { with } \\
\qquad W_{t}=\sum_{j=1}^{t}\left(q_{1}^{(j-1)^{\alpha_{1}}}-q_{1}^{j^{\alpha_{1}}}\right)\left(q_{2}^{(t-j)^{\alpha_{2}}}-q_{2}^{(t-j+1)^{\alpha_{2}}}\right)\end{array}$ & $\begin{array}{c}L_{D G}>0 \\
0<q_{1}, q_{2} \leq 1 \\
\alpha_{1}, \alpha_{2}>0\end{array}$ & $U C L_{G_{t}} / L C L_{G_{t}}=\mu_{0} \pm L_{D G} \frac{\sigma_{0}}{\sqrt{n}} \sqrt{\sum_{i=1}^{t} W_{i}^{2}}$ & $\begin{array}{l}U C L_{D G} / L C L_{D G}=\mu_{0} \pm L_{D G} \frac{\sigma_{0}}{\sqrt{n}} \sqrt{V} \\
\text { with } \\
\qquad V=\lim _{t \rightarrow \infty} \sum_{i=1}^{t} W_{i}^{2}\end{array}$ \\
\hline Shewhart-GWMA & $\begin{aligned} G_{t}=\sum_{i=1}^{t}\left(q_{1}^{(i-1)^{\alpha_{1}}}-q_{1}^{i^{\alpha_{1}}}\right) \bar{X}_{t-i+1}+q_{1}^{t^{\alpha_{1}}} \mu_{0} \\
\\
\quad \mathbf{O R} \\
\bar{X}_{t}=\frac{1}{n} \sum_{l=1}^{n} X_{t l}\end{aligned}$ & $\begin{array}{c}L_{S G}>0 \\
0<q_{1} \leq 1 \\
\quad \alpha_{1}>0 \\
k_{S}>0\end{array}$ & $\begin{array}{c}U C L_{G_{t}} / L C L_{G_{t}}=\mu_{0} \pm L_{G} \frac{\sigma_{0}}{\sqrt{n}} \sqrt{Q_{t}} \\
\text { OR } \\
U C L_{\bar{X}} / L C L_{\bar{X}}=\mu_{0} \pm k_{S} \frac{\sigma_{0}}{\sqrt{n}}\end{array}$ & $\begin{array}{c}U C L_{G} / L C L_{G}=\mu_{0} \pm L_{G} \frac{\sigma_{0}}{\sqrt{n}} \sqrt{Q} \\
\text { OR } \\
U C L_{\bar{X}} / L C L_{\bar{X}}=\mu_{0} \pm k_{S} \frac{\sigma_{0}}{\sqrt{n}}\end{array}$ \\
\hline GWMA-CUSUM & $\begin{array}{l}G C_{\bar{X}_{t}}^{+}=\max \left[0,\left(G_{t}-\mu_{0}-k_{G} \frac{\sigma_{0}}{\sqrt{n}} \sqrt{Q_{t}}\right)+G C_{\bar{X}_{t-1}}^{+}\right] \\
G C_{\bar{X}_{t}}^{-}=\max \left[0,\left(\mu_{0}-k_{G} \frac{\sigma_{0}}{\sqrt{n}} \sqrt{Q_{t}}-G_{t}\right)+G C_{\bar{X}_{t-1}}^{-}\right]\end{array}$ & $\begin{array}{l}k_{G}>0 \\
0<q_{1} \leq 1 \\
\quad \alpha_{1}>0 \\
\quad h>0\end{array}$ & $U C L_{G_{t}}=h \frac{\sigma_{0}}{\sqrt{n}} \sqrt{Q_{t}}$ & $U C L_{G}=h \frac{\sigma_{0}}{\sqrt{n}} \sqrt{Q}$ \\
\hline CUSUM-GWMA & $\begin{array}{l}C G_{\bar{X}_{t}}^{+}=\sum_{i=1}^{t}\left(q_{1}^{(i-1)^{\alpha_{1}}}-q_{1}^{i^{\alpha_{1}}}\right) C_{t-i+1}^{+}+q_{1}^{t \alpha_{1}} \mu_{0} \\
C G_{\bar{X}_{t}}=\sum_{i=1}^{t}\left(q_{1}^{(i-1)^{\alpha_{1}}}-q_{1}^{i \alpha_{1}}\right) C_{t-i+1}^{-}+q_{1}^{t \alpha_{1}} \mu_{0}\end{array}$ & $\begin{array}{c}L_{C G}>0 \\
0<q_{1} \leq 1 \\
\quad \alpha_{1}>0\end{array}$ & $U C L_{G_{t}} / L C L_{G_{t}}=\mu_{0} \pm L_{C G} \frac{\sigma_{0}}{\sqrt{n}} \sqrt{Q_{t}}$ & $U C L_{G} / L C L_{G}=\mu_{0} \pm L_{C G} \frac{\sigma_{0}}{\sqrt{n}} \sqrt{Q}$ \\
\hline
\end{tabular}


Note that when the underlying process parameters are known (i.e. Case K), control limits can easily be calculated and the process monitoring can take place immediately; however, when process parameters are unknown (i.e. Case U), a two phases approach needs to be implemented, see Jensen et $\mathrm{al}^{18}$ and Psarakis et $\mathrm{al}^{19}$. In Phase I, monitoring schemes are implemented retrospectively in order to estimate the distribution parameters using an IC reference sample. However, in Phase II, monitoring schemes are implemented prospectively to continuously monitor any departures from an IC state using the parameters estimated in Phase I. The operational procedure of the GWMA $\bar{X}$ scheme and its enhancements is as outlined in Figure 1. For Case K, only steps 1 to 5 are applicable; whereas in Case U, steps 0 to 5 are all applicable. Even though Table 1 and Figure 1 provide properties pertaining to GWMA-related schemes for the process mean only, other types of statistics can be done in a similar manner.

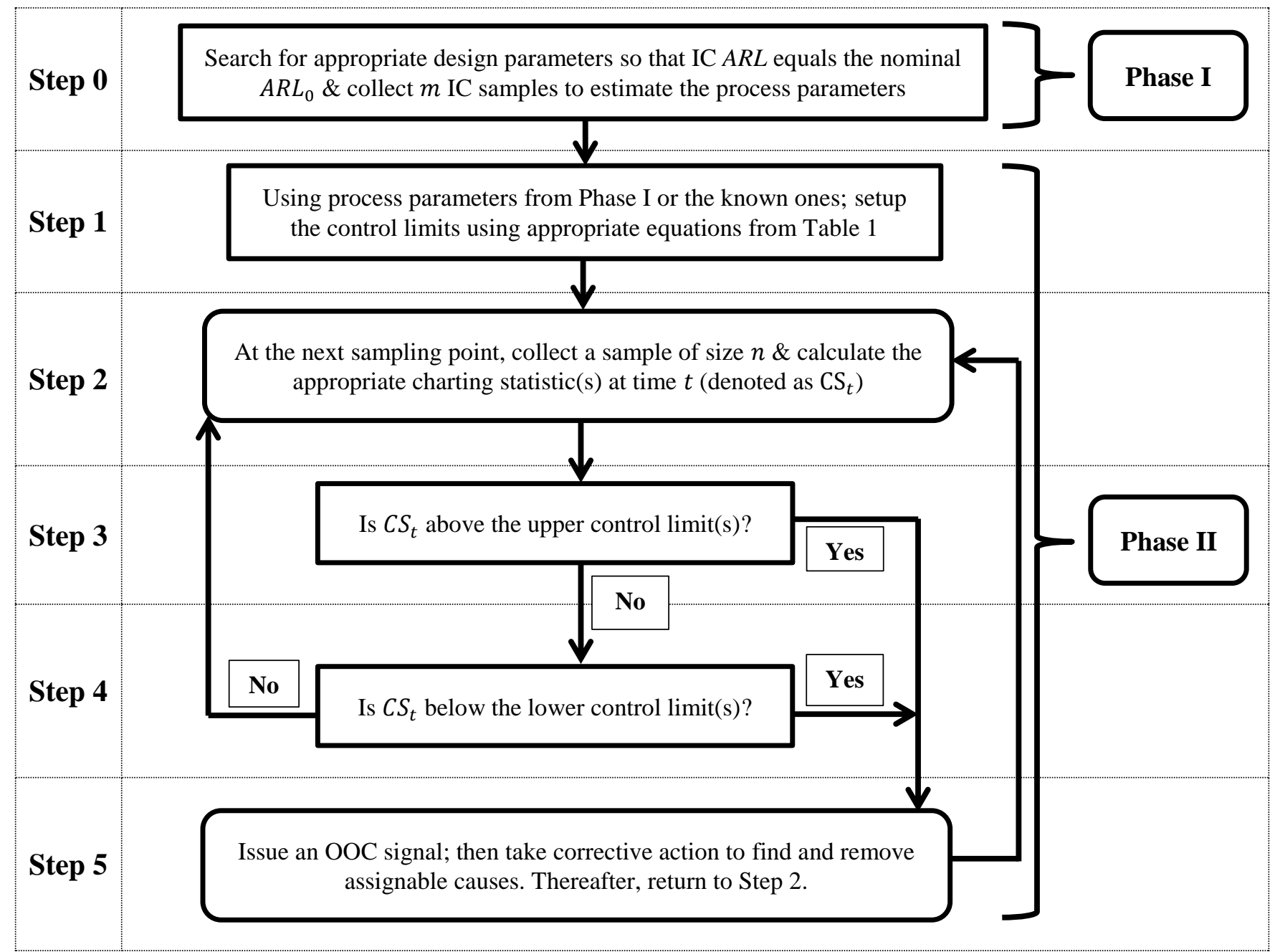

Figure 1: Flow chart illustrating the operational procedure of the GWMA scheme and its enhancements in Phase I and Phase II 


\subsection{Outline of the review}

The manner in which the review is structured by section is shown in Table 2. The "tick symbol" (i.e. " $\checkmark ")$ for items already treated and the "cross symbol" (i.e. " $\times$ ") for items untreated in the SPM literature.

Next, for ease in identifying the different types of GWMA-related schemes or their enhancements, in Table 3, these have been categorized with respect to: (i) the statistic of interest (i.e. location, variability or the joint location and variability), (ii) whether the underlying parameters are known or unknown (i.e. Case $\mathrm{K}$ or Case U), (iii) whether the observations are assumed to follow some parametric distribution or they are distribution-free, (iv) whether the observations are i.i.d. or autocorrelated (i.e., within sample serial correlation).

The journals or proceedings that have published researches on GWMA-related schemes and / or their enhancements are provided in Table 4 (as well as the total number of publications in each journal or proceedings). In Table 5, the list of researchers with at least two publications on GWMA-related schemes and / or their enhancements have been provided, including their corresponding affiliations.

Table 2: Outline of the review by section

\begin{tabular}{|c|c|c|c|c|c|c|}
\hline \multirow{6}{*}{3} & \multirow{6}{*}{ GWMA } & \multirow{3}{*}{3.1} & \multirow{3}{*}{ Parametric } & 3.1 .1 & Location & $\checkmark$ \\
\hline & & & & 3.1 .2 & Variability & $\checkmark$ \\
\hline & & & & 3.1 .3 & Joint location \& variability & $\checkmark$ \\
\hline & & \multirow{3}{*}{3.2} & \multirow{3}{*}{ Nonparametric } & & Location & $\sqrt{ }$ \\
\hline & & & & & Scale & $x$ \\
\hline & & & & & Joint location \& scale & $x$ \\
\hline \multirow{6}{*}{4} & \multirow{6}{*}{ DGWMA } & \multirow{3}{*}{4.1} & \multirow{3}{*}{ Parametric } & 4.1 .1 & Location & $\checkmark$ \\
\hline & & & & 4.1.2 & Variability & $\checkmark$ \\
\hline & & & & 4.1 .3 & Joint location \& variability & $\checkmark$ \\
\hline & & \multirow{3}{*}{4.2} & \multirow{3}{*}{ Nonparametric } & & Location & $\checkmark$ \\
\hline & & & & & Scale & $x$ \\
\hline & & & & & Joint location \& scale & $x$ \\
\hline \multirow{6}{*}{5} & \multirow{6}{*}{ Shewhart-GWMA } & & \multirow{3}{*}{ Parametric } & 5.1 & Location & $\checkmark$ \\
\hline & & & & & Variability & $x$ \\
\hline & & & & 5.2 & Joint location \& variability & $\checkmark$ \\
\hline & & \multirow{3}{*}{\multicolumn{2}{|c|}{ Nonparametric }} & & Location & $\times$ \\
\hline & & & & & Scale & $x$ \\
\hline & & & & & Joint location \& scale & $x$ \\
\hline \multirow{6}{*}{6} & \multirow{6}{*}{$\begin{array}{l}\text { GWMA-CUSUM \& } \\
\text { CUSUM-GWMA }\end{array}$} & & \multirow{3}{*}{ Parametric } & 6.1 & Location & $\checkmark$ \\
\hline & & & & 6.2 & Variability & $\checkmark$ \\
\hline & & & & & Joint location \& variability & $\times$ \\
\hline & & & \multirow{3}{*}{ Nonparametric } & & Location & $x$ \\
\hline & & & & & Scale & $x$ \\
\hline & & & & & Joint location \& scale & $x$ \\
\hline
\end{tabular}


Table 3: Classification of articles discussing GWMA-related monitoring schemes in SPM (sorted chronologically)

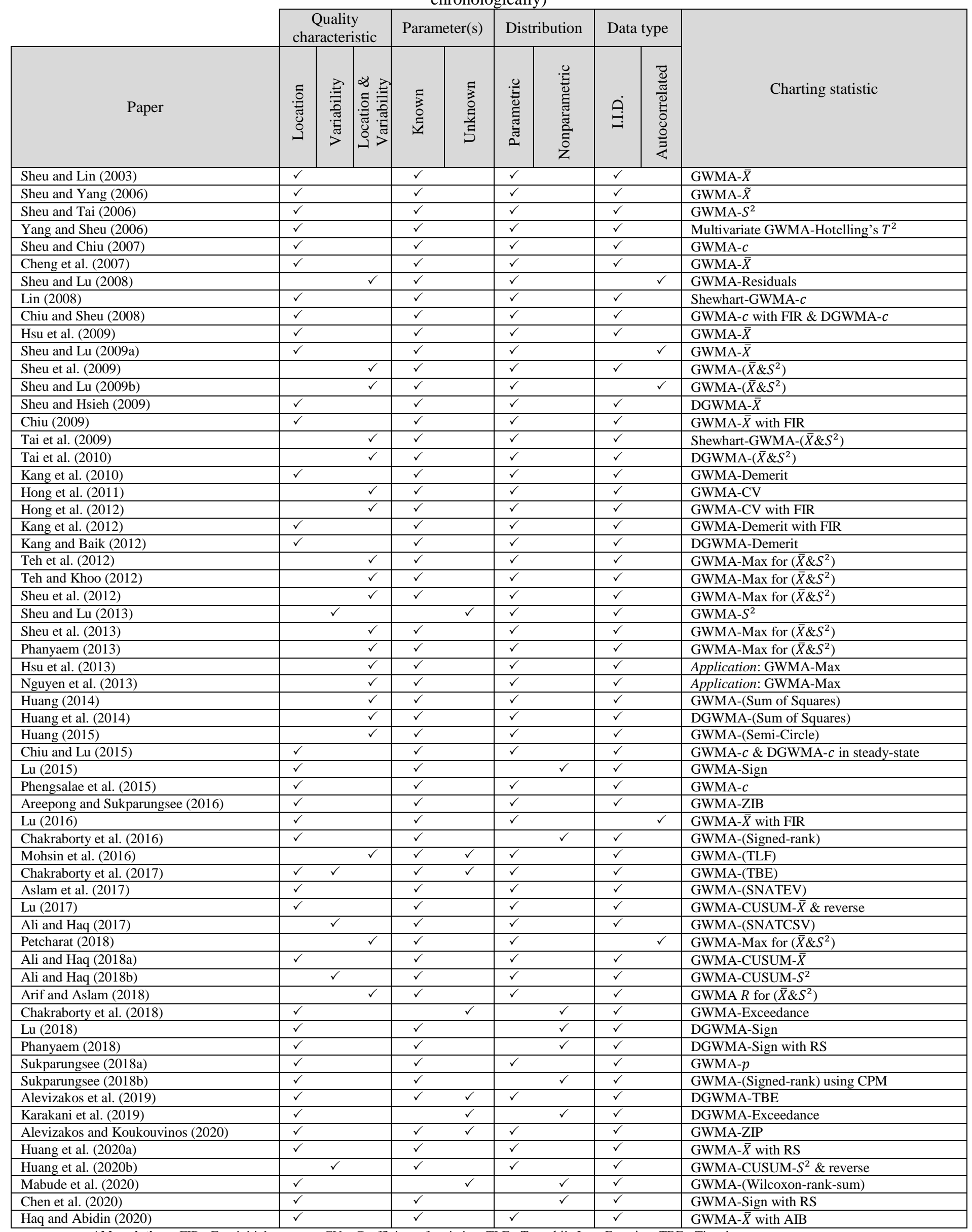

Haq and Abidin (2020)

Abbreviations: FIR - Fast initial response; CV - Coefficient of variation; TLF - Taguchi's Loss Function; TBE - Time between events;

SNATEDV - Standard normal approximation of transformed exponential variables; RS - Repetitive sampling; SNATCSV - Standard normal approximation of transformed chi-squared variables; CPM - Change point model; ZIB - Zero Inflated Binomial; ZIP - Zero Inflated Poisson; AIB Auxiliary-information-based. 
Table 4: Journals / conference proceedings that published researches on GWMA-related monitoring schemes

\begin{tabular}{|l|c|}
\hline \multicolumn{1}{|c|}{ Journal / Conference proceedings title } & $\begin{array}{c}\text { Number of } \\
\text { publications }\end{array}$ \\
\hline Quality and Reliability Engineering International & 9 \\
\hline Communications in Statistics - Theory and Methods & 9 \\
\hline Communications in Statistics - Simulation and Computation & 6 \\
\hline Advanced Materials Research & 2 \\
\hline Applied Mechanics and Materials & 2 \\
\hline Computers \& Industrial Engineering & 2 \\
\hline Journal of Applied Statistics & 2 \\
\hline Journal of Statistical Computation and Simulation & 2 \\
\hline Quality Engineering & 2 \\
\hline The International Journal of Advanced Manufacturing Technology & 2 \\
\hline Advanced Science Letters & 1 \\
\hline Asia Pacific Journal of Operational Research & 1 \\
\hline Complexity & 1 \\
\hline Expert Systems with Applications & 1 \\
\hline Far East Journal of Mathematical Sciences & 1 \\
\hline International Journal of Industrial Engineering Computation & 1 \\
\hline International Journal of Mathematical, Computational, Physical and Quantum Engineering & 1 \\
\hline International Journal of Quality and Reliability Management & 1 \\
\hline Journal of Computational and Theoretical Nanoscience & 1 \\
\hline Journal of Engineering Manufacture & 1 \\
\hline Journal of Statistics and Management Systems & 1 \\
\hline Matter: International Journal of Science and Technology & 1 \\
\hline Quality Technology \& Quantitative Management & 1 \\
\hline Risk and Decision Analysis & 1 \\
\hline Songklanakarin Journal of Science and Technology & 1 \\
\hline Thailand Statistician & $\mathbf{6 1}$ \\
\hline Various international conference proceedings & 1 \\
\hline & \\
\hline
\end{tabular}

Table 5: Researchers in SPM with at least two publications on GWMA-related monitoring schemes and their corresponding affiliations

\begin{tabular}{|c|c|c|}
\hline Author & Affiliation & $\begin{array}{c}\text { Number of } \\
\text { publications }\end{array}$ \\
\hline Sheu, S.-H. & National Taiwan University of Science and Technology, Taiwan & 15 \\
\hline Lu, S.-L. & Aletheia University, Taiwan & 13 \\
\hline Huang, C.-J. & Jinwen University of Science and Technology, Taiwan & 8 \\
\hline Tai, S.-H. & Lunghwa University of Science and Technology, Taiwan & 5 \\
\hline Kang, H.W. & Hanyang University, Korea & 5 \\
\hline Baik, J.W. & Hanyang University, Korea & 4 \\
\hline Chiu, W.-C. & Aletheia University, Taiwan & 4 \\
\hline Haq, A. & Quaid-i-Azam University, Pakistan & 4 \\
\hline Human, S.W. & University of Pretoria, South Africa & 4 \\
\hline Lin, T.-C. & Lunghwa University of Science and Technology, Taiwan & 4 \\
\hline Shu, M.-H. & National Kaohsiung University of Applied Sciences, Taiwan & 4 \\
\hline Sukparungsee, $\mathrm{S}$. & King Mongkut's University of Technology North Bangkok & 4 \\
\hline Ali, R. & Quaid-i-Azam University, Pakistan & 3 \\
\hline Aslam, M. & King Abdulaziz University, Saudi Arabia & 3 \\
\hline Balakrishnan, N. & McMaster University, Canada & 3 \\
\hline Chakraborty, N. & University of Pretoria, South Africa & 3 \\
\hline Chen, J.-H. & Shih Chien University, Taiwan & 3 \\
\hline Hsieh, Y.-T. & Lunghwa University of Science and Technology, Taiwan & 3 \\
\hline Hsu, B.-M. & Cheng Shiu University, Taiwan & 3 \\
\hline Kang, C.W. & Hanyang University, Korea & 3 \\
\hline Areepong, Y. & King Mongkut's University of Technology North Bangkok & 2 \\
\hline Alevizakos, V. & National Technical University of Athens, Greece & 2 \\
\hline Hong, E.P. & Hanyang University, Korea & 2 \\
\hline Hsu, T.-S. & National Taiwan University of Science and Technology, Taiwan & 2 \\
\hline Jun, C.-H. & POSTECH, Republic of Korea & 2 \\
\hline Khoo, M.B.C. & Universiti Sains Malaysia, Malaysia & 2 \\
\hline Koukouvinos, C. & National Technical University of Athens, Greece & 2 \\
\hline Nam, S.H. & Korea Institute of Industrial Technology, Korea & 2 \\
\hline Nguyen, T.-L. & National Kaohsiung University of Applied Sciences, Taiwan & 2 \\
\hline Phanyaem, S. & King Mongkut's University of Technology North Bangkok, Bangkok & 2 \\
\hline Teh, S.Y. & Universiti Sains Malaysia, Malaysia & 2 \\
\hline Yang, L. & St John's University, Taiwan & 2 \\
\hline
\end{tabular}




\section{GWMA schemes}

\subsection{Parametric schemes}

\subsubsection{Location}

\section{Process mean}

Apart from introducing the GWMA scheme to the SPM literature, Sheu and Lin $^{9}$ showed that when $\alpha_{1}=1$, the GWMA $\bar{X}$ scheme reduces to the EWMA $\bar{X}$ scheme; whereas when $\alpha_{1}=1$ and $q_{1}=0$ it reduces to the Shewhart $\bar{X}$ scheme. The latter holds for all different types of GWMA-related schemes. Apart from showing that the GWMA $\bar{X}$ scheme outperforms the corresponding EWMA $\bar{X}$ scheme in many situations, Sheu and $\operatorname{Lin}^{9}$ demonstrated that it also outperforms the Shewhart $\bar{X}$ scheme with and without runs-rules. The performance of the GWMA $\bar{X}$ scheme is compared with the corresponding Shewhart, EWMA and CUSUM $\bar{X}$ schemes in Cheng et $\mathrm{al}^{20}$ and Hsu et $\mathrm{al}^{21}$; and it is observed that it has a better performance in many situations as compared to the others. Note that Hsu et $\mathrm{al}^{21}$ is a similar, but extended version of Cheng et $\mathrm{al}^{20}$ s $\mathrm{s}$ study. Next, $\mathrm{Chiu}^{22}$ investigated numerous asymptotic and time-varying GWMA schemes with different fast initial response (FIR) strategy to remedy start-up problems. Using the $A R L$ and $S D R L$ metrics, it is observed that time-varying GWMA $\bar{X}$ schemes are excellent for small shifts detection, and those with FIR are best for large shifts detection. The GWMA scheme based on a regression-type estimator of the process mean with auxiliary-information-based (AIB) variable under some specific conditions of correlation is investigated in Haq and $\operatorname{Abidin}^{23}$. For processes with start-up problems, a FIR approach is also incorporated and it is shown that it uniformly outperforms the basic GWMA scheme; however, it outperforms the EWMA $\bar{X}$ scheme with AIB in most situations.

Except where stated differently, the existing GWMA-related schemes are based on simple random sampling (SRS) with none on structured sampling methods. Hence, Huang et $\mathrm{al}^{24}$ provides a thorough discussion on how to implement a repetitive sampling procedure for the GWMA $\bar{X}$ scheme. Using the $A R L$ and average sample size (ASS) metrics, it is shown that it outperforms the corresponding GWMA and hybrid EWMA schemes based on the SRS method in detecting small shifts. Moreover, it is also shown that the GWMA scheme based on SRS is associated with higher sampling costs.

For non-normal data, Aslam et $\mathrm{al}^{25}$ proposed a GWMA $\bar{X}$ scheme with a standard normal transformation of observations collected from an exponentially distributed data. Using the ARL metric, they showed that their scheme outperforms the corresponding EWMA scheme in many situations.

There is a single publication on multivariate GWMA (MGWMA) scheme and it is reported in Yang and $\mathrm{Sheu}^{26}$; where they noted that SPM aims to reduce variability by monitoring and eliminating assignable causes of variation; while engineering process control (EPC) aims to minimize variability by adjusting process variables to keep the process output on target. Moreover, it is shown in Yang and Sheu $^{26}$ that the multivariate EPC (MEPC) combined with the MGWMA scheme has a better small 
shifts detection ability in the mean vector than the corresponding MEPC combined with the multivariate EWMA as well as the MEPC combined with the Hotelling's chi-square schemes.

The abovementioned articles in this subsection are based on i.i.d. observations used to compute the process mean. However, in real-life, sequentially sampled observations tends to exhibit serial dependence or autocorrelation. Thus, Sheu and $\mathrm{Lu}^{27}$ and $\mathrm{Lu}^{28}$ proposed GWMA $\bar{X}$ schemes to monitor the mean of observations from an autoregressive moving average process of order $(1,1)$, denoted as $\operatorname{ARMA}(1,1)$ without and with FIR, respectively. The GWMA $\bar{X}$ scheme with FIR detects OOC observations faster than the one without FIR; however, for high levels of autocorrelation, these are similar in performance.

\section{Process median}

Unlike the process mean, the process median tends to be preferred in some situations due to its outlier-resistant property. Sheu and Yang ${ }^{29}$ showed that the GWMA median scheme outperforms the corresponding EWMA (including the one with FIR) and the Shewhart median schemes in many situations. Note though, the GWMA $\bar{X}$ scheme has a better OOC detection ability while the GWMA median scheme performs best when the process is subjected to outliers. Moreover, the quality cost model implemented with contaminated normal distribution shows that the GWMA median scheme is more economical with respect to the average quality cost as compared to the GWMA $\bar{X}$ scheme.

\section{Time-between-events}

To ensure $A R L$-unbiased OOC performance, Chakraborty et $\mathrm{al}^{30}$ proposed a one-sided GWMA scheme for monitoring time-between-events (TBE) based on the gamma distribution for Cases $\mathrm{K}$ and U. It is observed that the estimation of the unknown parameter from an IC Phase I sample affects the GWMA TBE scheme's performance in Phase II. Using the ARL, SDRL and percentile run-length $(P R L)$, it is shown that the GWMA TBE scheme is better than the corresponding EWMA and Shewhart schemes in both Cases $\mathrm{K}$ and $\mathrm{U}$.

\section{Attributes data}

When the characteristic to be monitored is in the form of count data and under the assumption of a Poisson distribution; using simulation, Sheu and $\mathrm{Chiu}^{31}$ showed that while the GWMA $c$ scheme outperforms the corresponding Shewhart and EWMA $c$ schemes in detecting all shifts values, it outperforms the DEWMA $c$ scheme in detecting small-to-moderate shifts only. However, using Markov chain approach discussed in Brooks and Evans ${ }^{32}$, Phengsalae et $\mathrm{al}^{33}$ showed that for different nominal $A R L_{0}$ values, the GWMA $c$ scheme tend to outperform the EWMA $c$ scheme for small shifts only. Moreover, the simulation approach tends to be time consuming in terms of CPU time as compared to Markov chain approach, i.e. takes 10-to-60 minutes per case study for simulation as compared to 1-to-2 minutes for Markov chain approach. Next, Chiu and Sheu ${ }^{34}$ investigated numerous asymptotic and time-varying GWMA $c$ schemes with different FIR features to remedy start-up problems. Using the zero-state $A R L$ and $S D R L$ metrics, it is observed that the GWMA $c$ scheme with 
time-varying limits or FIR features are best for large shifts detections. When the characteristic to be monitored is in the form of number nonconforming and under the assumption of a binomial distribution; using both Markov chain and simulation approaches, Sukparungsee ${ }^{35}$ proposed the GWMA $p$ scheme and showed that it outperforms the corresponding EWMA $p$ scheme for small shifts. Also, the Markov chain approach is computationally time efficient than the simulation approach.

In the case of high quality processes, where a large number of zero nonconforming observations exist, the $c$ and $u$ schemes result in excessive false alarms, hence a zero-inflated Poisson (ZIP) distribution is often used to model and monitor count data with such a large number of zeros. In a ZIP model, some random shocks occur independently with probability $p$ and the number of nonconformities follows a Poisson distribution with parameter $\lambda$. Thus, the GWMA ZIP scheme is proposed by Alevizakos and Koukouvinos ${ }^{36}$ to monitor $p$ and $\lambda$ in Cases $\mathrm{K}$ and $\mathrm{U}$ for upwards shifts. A comparison with the corresponding upper-sided Shewhart, CUSUM and DEWMA schemes indicates that, in many situations, the GWMA ZIP scheme is more effective when both parameters are monitored. However, the CUSUM ZIP scheme is more efficient for small shifts when either $p$ or $\lambda$ is of interest; while either the Shewhart or GWMA ZIP scheme is always more efficient for large shifts. Similarly, the zero-inflated binomial (ZIB) distribution has two parameters, i.e. excess zeros occur independently with probability $\pi$ and the number of nonconformities follows a binomial distribution with parameter $p$. Hence, Areepong and Sukparungsee ${ }^{37}$ proposed a GWMA ZIB scheme using both Markov chain and simulation approaches and observed that they yields approximately the same runlength results. Moreover, the GWMA ZIB scheme outperforms the EWMA ZIB scheme in detecting small-to-moderate parameter shifts in Case K. Finally, the Markov chain approach is computationally time efficient than the simulation approach.

\section{Demerit system}

A demerit scheme is used to monitor a demerit system containing different types of defects in an inspection unit. For instance, defects are classified in terms of categories or classes, e.g. 'Very serious', 'Serious', 'Moderately serious' and 'Minor'. Kang et al ${ }^{38}$ proposed the GWMA demerit scheme to monitor the mean demerit number per unit by classes. It is shown that, in many situations, the GWMA demerit scheme has a better OOC performance than the Shewhart and EWMA demerit schemes. Next, Kang et $\mathrm{al}^{39}$ investigated the GWMA demerit scheme with a FIR feature (i.e. 50\% head-start feature). Using $A R L$ and SDRL, they showed that the GWMA demerit scheme with a FIR feature is more effective than the Shewhart, EWMA and GWMA demerit schemes without a FIR feature.

\subsubsection{Variability}

Sheu and $\mathrm{Tai}^{40}$ proposed the GWMA $S^{2}$ scheme and showed that it outperforms the corresponding EWMA scheme in detecting OOC observations especially for small shifts. Next, Sheu and $\mathrm{Lu}^{41}$ used 
an unbiased estimator of the process variance to propose the one-sided GWMA $S^{2}$ scheme and showed that it yields better $A R L$ s than the basic EWMA and exponential weighted mean square deviation schemes. Next, Ali and Haq ${ }^{42}$ proposed a one- and two-sided GWMA $S^{2}$ schemes which are based on applying the normal approximation to the distributions of the logarithms of the weighted sum of chi-squared random variables. The EWMA version with these types of weighted scores was first discussed in Huwang et $\mathrm{al}^{43}$. It is observed that a properly designed one- or two-sided GWMA $S^{2}$ scheme has a better OOC performance than the corresponding EWMA schemes in detecting small shifts. Finally, it is worth mentioning that Chakraborty et $\mathrm{al}^{30}$ briefly discussed how the GWMA TBE scheme can be used to monitor downwards shifts in the variance for normally distributed data in Case $\mathrm{K}$ and they commented on how this can be extended to the Case $\mathrm{U}$ scenario.

\subsubsection{Location and Variability}

\section{Mean and variance using separate charting statistics}

The combined GWMA $\left(\bar{X} \& S^{2}\right)$ scheme to jointly monitor the process mean and variability of i.i.d. observations using separate charting statistics at each sampling point was proposed by Sheu et $\mathrm{al}^{44}$. It is shown that, in many situations, it has a better OOC $A R L$ performance as compared to the corresponding combined EWMA $\left(\bar{X} \& S^{2}\right)$ scheme. Next, the corresponding studies to jointly monitor the process mean and variability of residuals \& autocorrelated actual observations were investigated in Sheu and $\mathrm{Lu}^{45,46}$, respectively; assuming an $\operatorname{ARMA}(1,1)$ model for the time series data. In each investigated instance, the GWMA schemes were shown to have a better OOC ARL performance than the corresponding EWMA schemes.

\section{Mean and variance using a single charting statistic}

Both papers by Sheu et $\mathrm{al}^{47}$ and Teh et $\mathrm{al}^{48}$ proposed a GWMA scheme to monitor the mean and variance of i.i.d. observations using a single plotting statistic; which is based on either the maximum of the transformed mean or variance, i.e. a GWMA Max scheme. The transformed mean and variance values of the Max statistic are obtained using an inverse standard normal distribution and a chi-square distribution, respectively. Note though, Sheu et $\mathrm{al}^{47}$ compared the GWMA Max scheme to the EWMA Max scheme; while Teh et $\mathrm{al}^{48}$ compared it to the GWMA $\left(\bar{X} \& S^{2}\right)$ scheme for separately monitoring the mean and variance by Sheu et $\mathrm{al}^{44}$. In many situations the GWMA Max scheme has a better OOC $A R L$ and SDRL performance; however, they have the same diagnostic ability (source of the assignable cause(s) and the direction of the shift) as their competitors. Real-life case studies of the GWMA Max scheme can be found in Nguyen et $\mathrm{al}^{49}$ and Hsu et $\mathrm{al}^{50}$ using the thickness of the coating layer of tablets and the quality of displays from Thin Film Transistor - Liquid Crystal Display (TFT-LCD) datasets, respectively. Next, Teh and Khoo ${ }^{51}$ considered the Log-Normal and Gamma distributions to study the robustness and the effect of skewed distributions on the GWMA Max scheme. In many situations, the results showed that the GWMA Max scheme has lower false alarm rates (or similarly, higher IC ARLs) for more levels of skewness when compared to the EWMA Max scheme. Some 
additional comparisons between the performance of the GWMA and EWMA Max schemes when the underlying observations are from i.i.d. and autoregressive of order $p \in\{2,3\}$ processes can be found in Phanyaem ${ }^{52}$ and Petcharat ${ }^{53}$, respectively.

Similar to Teh et $\mathrm{al}^{48}$ and Sheu et $\mathrm{al}^{47}$, another GWMA Max scheme; however, with a different plotting statistics was proposed by Sheu et $\mathrm{al}^{54}$. This latter Max statistic is based on $\max \left\{\left(\frac{A}{\sigma_{A}}\right)^{2},\left(\frac{B}{\sigma_{B}}\right)^{2}\right\}$, while that of Teh et $\mathrm{al}^{48}$ and Sheu et al ${ }^{47}$ is based on $\max \{|A|,|B|\}$, where $A$ and $B$ are the transformed values of GWMA statistics for the transformed mean and variance derived via the inverse standard normal and chi-square distributions, and $\sigma_{A} \& \sigma_{B}$ are their corresponding standard deviations, respectively. Sheu et $\mathrm{al}^{54}$ showed that the GWMA Max scheme has a better $A R L$ performance than the EWMA Max scheme; note though, the diagnostic analysis was not considered. Huang ${ }^{55,56}$ proposed a GWMA scheme with a single statistic which is based on the sum of squares (SoS) of the GWMA statistics and the semi-circle (SC) concept, respectively. Using the ARL and $S D R L$, it is shown that the GWMA schemes have a better detection ability than the corresponding EWMA schemes, especially for small shifts; however, they have similar diagnostics abilities. Next, Mohsin et a ${ }^{57}$ proposed a GWMA scheme based on the Taguchi's loss function (TLF) using a single statistic (which has a non-central chi-squared distribution) in Case U. The GWMA TLF scheme outperforms the fixed parameter EWMA SC scheme; while in some situations, it is outperformed by the VSI EWMA scheme - the authors stated that this is due to the added VSI feature.

Since the inverse erf function has a better performance than the power transformation or the Box-Cox transformation when the Weibull distribution parameter is larger than one; hence, Arif and Aslam ${ }^{58}$ used the inverse erf function to transform the Weibull distributed data to approximately normally distributed ones. Thereafter, a GWMA range scheme is used to monitor the range of either the transformed mean or variability, i.e. $U=\max \{|A|,|B|\}$ and $V=\min \{|A|,|B|\}$, where $A$ and $B$ are the transformed values of GWMA statistics for the mean and variance; so that $R=U-V$. Using the $A R L$ and $S D R L$, it is shown that the GWMA range scheme is more efficient than its EWMA counterpart in many situations.

\section{Coefficient of variation}

For processes where the mean and variability parameters vary in a fixed proportional way when the process is IC, it is more reasonable to monitor the coefficient of variation (CV). Hong et $\mathrm{al}^{59}$ showed that the Shewhart CV scheme is inefficient in monitoring small shifts; hence, they proposed the GWMA CV scheme. Using the $A R L, S D R L$ and ratios of the $A R L s$, it is shown that, in many situations, the GWMA CV scheme has a better OOC performance as compared to the EWMA and DEWMA CV schemes. Next, Hong et $\mathrm{al}^{60}$ incorporated a FIR feature to the GWMA CV scheme and they showed that it has a significantly improved OOC performance compared to the DEWMA and GWMA schemes without a FIR feature. 


\subsection{Nonparametric schemes}

Currently, the only contributions that consider the monitoring of a nonparametric statistic using a GWMA scheme are all dedicated to the monitoring of the process location. As far as we know, no contribution has been devoted so far to the monitoring of the process dispersion that combines a nonparametric statistic and a GWMA scheme.

A GWMA sign scheme was proposed by $\mathrm{Lu}^{61}$ who showed that it is a good alternative to a parametric GWMA $\bar{X}$ scheme. Moreover, (for certain values of $q$ and $\alpha$ ) it has a better OOC detection ability than the GWMA $\bar{X}$ scheme in many situations. However, for processes with a distribution that is skewed to the right, the GWMA sign scheme is not as effective as the GWMA $\bar{X}$ scheme in detecting assignable causes. Distributions that were used are Normal, Laplace, Uniform and Gamma. Chen et $\mathrm{al}^{62}$ proposed a GWMA sign scheme using repetitive sampling and they showed that it yields a lower number of repetitive samples than its competitors. Taking into account the shapes of the Normal, Student's $t$ - and Gamma distribution, Chen et $\mathrm{al}^{62}$ used the ARL and ASS metrics to show that the GWMA sign scheme with repetitive sampling outperforms the corresponding EWMA scheme based on SRS and repetitive sampling methods as well as the GWMA scheme based on SRS in detecting small shifts. Also, it has better small shifts detection ability as compared to the double sampling EWMA sign scheme; but for other levels of shifts, the converse is true.

Chakraborty et $\mathrm{al}^{63}$ proposed a GWMA signed-rank scheme and showed that it is IC robust (so is the GWMA sign scheme), while the GWMA $\bar{X}$ scheme is not. Using the Normal, Student's $t$-, Logistic and Uniform distributions, it is shown that the GWMA signed-rank scheme outperforms the GWMA sign scheme in many situations; however, when using the Laplace distribution, the GWMA sign scheme has a slightly better small shifts detection ability. Next, using the Exponential, Gamma, LogNormal and Weibull distributions, Sukparungsee ${ }^{64}$ studied its IC robustness and taking into account the change-point model to calculate the OOC ARLs. The GWMA signed-rank scheme is shown to have a uniformly better OOC performance than the GWMA sign scheme for all considered distributions and shift values. While the GWMA signed-rank scheme is superior for shifts of size 0.25 or less; the corresponding EWMA signed-rank scheme outperforms it for moderate-to-large shifts (this is inconsistent with the results in Table 3 of Chakraborty et al ${ }^{63}$ ). Note that Sukparungsee ${ }^{64}$ considered more shift values as compared to Chakraborty et $\mathrm{al}^{63}$.

When parameters are unknown, the median test (i.e. sign or signed-rank) schemes are not applicable. As an alternative to the two-sample location shift parametric $t$-test, the Exceedance (EX) and Wilcoxon rank-sum (WRS) tests are usually recommended when the underlying process distribution is non-normal. The GWMA scheme based on the exceedance statistic (two-sample tests based on the number of observations from one of the samples that exceed a specified $r^{\text {th }}$ order statistic of the other sample) was proposed by Chakraborty et $\mathrm{al}^{65}$. An OOC performance is conducted (with $r=0.25,0.5$, 0.75 ) using the $A R L$ and $M R L$ metrics. The GWMA EX scheme is shown to outperform the EWMA 
EX and Shewhart $\bar{X}$ schemes using the Normal, Logistic, Uniform, Laplace and Gamma distributions in many situations. Moreover, the Case U GWMA $\bar{X}$ scheme is shown to be not IC robust especially for skewed distributions while the GWMA EX scheme is IC robust to non-normality and has a better performance than the EWMA EX scheme in many situations. Next, the GWMA WRS scheme was proposed by Mabude et $\mathrm{al}^{66}$, with the Normal, Student's $t$-, Gamma, Log-logistic and Weibull distributions used to show the IC robustness and to study the OOC performance. It is shown that the GWMA WRS scheme has a significantly better OOC performance than the corresponding parametric and nonparametric Shewhart, EWMA and CUSUM schemes. Also, the effect of the Phase I reference sample size on the Phase II test samples' OOC performance is provided.

\section{DGWMA schemes}

\subsection{Parametric schemes}

The only research works that exist for DGWMA parametric schemes are on monitoring location as well as jointly monitoring location and variability.

\subsubsection{Location}

\section{Process mean}

Sheu and $\mathrm{Hsieh}^{67}$ proposed an extension to the GWMA scheme called the DGWMA $\bar{X}$ scheme. Using $A R L$ and SDRL metrics, this extension is shown to be superior to the GWMA $\bar{X}$ scheme in detecting medium-to-large shifts; but for small shifts, the converse is true. Note though, compared to the DEWMA scheme, the DGWMA scheme is superior for small-to-moderate shifts; and the converse is true for large shifts. Chiu ${ }^{22}$ showed that the DGWMA scheme has the best performance for moderate shifts detections as compared to the time-varying GWMA scheme which is excellent for small shifts as well as the GWMA scheme with FIR which is the best scheme for large shifts detection.

\section{Time-between-events}

Alevizakos et al ${ }^{68}$ proposed the one-sided ARL-unbiased DGWMA TBE scheme and they showed that it is not IC robust and it has uniformly better zero-state $A R L$ values as compared to the DEWMA TBE scheme. Also, it has a better steady-state $A R L$ performance than the DEWMA TBE scheme for smallto-moderate shifts; but the converse is true for other shifts. In some situations, the GWMA TBE scheme has a slight advantage over the DGWMA TBE scheme for (very small)-to-small shifts, but the converse is true for other shifts.

\section{Attributes data}

Chiu and Sheu ${ }^{34}$ studied the zero-state performance of the DGWMA $c$ scheme, where it is shown that it is preferred for small downwards shifts over the GWMA $c$ scheme with time-varying limits or FIR feature. The corresponding steady-state performance is discussed in Chiu and $\mathrm{Lu}^{69}$, where it is shown that it is preferred for downward shifts, while the GWMA $c$ scheme is more competitive for upward shifts. 


\section{Demerit system}

Kang and Baik $^{70}$ proposed the DGWMA demerit scheme and they showed that, in many situations, it has better performance in detecting small shifts in the mean demerit number per unit by classes than the GWMA, EWMA and Shewhart schemes discussed in Kang et $\mathrm{al}^{38}$.

\subsubsection{Location and variability}

Tai et $\mathrm{al}^{71}$ proposed a DGWMA $\left(\bar{X} \& S^{2}\right)$ scheme and showed that, in many situations, it has a better OOC ARL performance as compared to the corresponding GWMA $\left(\bar{X} \& S^{2}\right)$ scheme by Sheu et $\mathrm{al}^{44}$. Next, Huang et $\mathrm{al}^{72}$ proposed a DGWMA SoS scheme and showed that it has a better $A R L$ and $S D R L$ detection ability than the corresponding DEWMA and GWMA SoS schemes in many situations.

\subsection{Nonparametric schemes}

The research works that exist for DGWMA-type nonparametric schemes are on monitoring the location parameter only.

$\mathrm{Lu}^{73}$ proposed a DGWMA sign scheme and showed that it is more sensitive than the corresponding EWMA, GWMA and DEWMA schemes in many situations. Phanyaem ${ }^{74}$ briefly discussed the DGWMA sign scheme with repetitive sampling and showed that it is more sensitive than the corresponding DEWMA sign scheme in many situations. Next, Karakani et $\mathrm{al}^{75}$ proposed the DGWMA EX scheme to monitor unknown median shifts in a process (with $r=0.25,0.5,0.75$ ). Moreover, for comparison purpose, the DEWMA EX scheme is also proposed and it is shown to be inferior as compared to the former in many situations. Using the $A R L$ and $M R L$, it is shown that the DGWMA $\bar{X}$ scheme in Case U is not IC robust, while the DGWMA EX scheme is IC robust to nonnormality. The same distributions as those in Chakraborty et $\mathrm{al}^{65}$ are considered and the DGWMA EX scheme is observed to have more favourable results than the GWMA and EWMA EX schemes.

\section{Shewhart-GWMA schemes}

Currently, no research work exists for nonparametric Shewhart-GWMA schemes. However, for parametric ones, some based on monitoring location as well as location and variability exist.

\subsection{Location}

\section{Process mean}

The composite Shewhart-GWMA $\bar{X}$ scheme (with and without runs-rules) was first studied in Sheu and $\operatorname{Lin}^{9}$ and shown to be more sensitive than the Shewhart schemes (with and without runs rules) and the GWMA scheme. Due to the complexity in implementation and excessive false alarms along with a very minor OOC improvement, the use of composite Shewhart-GWMA $\bar{X}$ schemes with runs-rules is not advised.

\section{Attributes data}

$\operatorname{Lin}^{15}$ showed that the composite Shewhart-GWMA $c$ scheme integrated with the sensitizing rules by Nelson ${ }^{76}$ does increase the detection ability; however, it simultaneously degrades the IC values so that 
the scheme yields excessive false alarms. Since the implementation of the composite ShewhartGWMA $c$ scheme is relatively complex, it is neither not advised to use it in real-life applications.

\subsection{Location and variability}

Tai et $\mathrm{al}^{77}$ proposed a composite Shewhart-GWMA $\left(\bar{X} \& S^{2}\right)$ scheme using separate charting statistics at each sampling point and they showed that it is more effective in quickly detecting OOC observations compared to the corresponding composite Shewhart-EWMA $\left(\bar{X} \& S^{2}\right)$ scheme.

\section{GWMA-CUSUM schemes and its reverse version}

Currently, no research work exist for nonparametric statistics using GWMA-CUSUM schemes. However, for parametric ones, some based on monitoring location and monitoring variability exist.

\subsection{Location}

$\mathrm{Lu}^{16}$ proposed the mixed GWMA-CUSUM $\bar{X}$ scheme and its reverse version (CUSUM-GWMA $\bar{X}$ scheme) to monitor individual observations. It is shown (using $A R L$ only) that, in many situations, this scheme provides better OOC detection ability than the basic GWMA, EWMA and CUSUM schemes, as well as the mixed EWMA-CUSUM and CUSUM-EWMA $\bar{X}$ schemes. Moreover, the CUSUMGWMA scheme is shown to yield a slightly better OOC ARL performance over the corresponding GWMA-CUSUM scheme in many situations. At the same time, but independently, Ali and Haq ${ }^{17}$ also proposed the GWMA-CUSUM $\bar{X}$ scheme to monitor the process mean; however, of subgroup observations. Note though, Ali and $\mathrm{Haq}^{17}$ did not consider the reverse CUSUM-GWMA $\bar{X}$ scheme.

\subsection{Variability}

Ali and $\mathrm{Haq}^{78}$ proposed the mixed GWMA-CUSUM $S^{2}$ scheme (with and without FIR) to monitor upwards shifts for subgroup observations and showed that it yields better OOC detection ability than the CUSUM and mixed CUSUM-EWMA $S^{2}$ schemes. Note that Ali and $\mathrm{Haq}^{78}$ did not consider the mixed CUSUM-GWMA $S^{2}$ scheme. Next, Huang et $\mathrm{al}^{79}$ proposed the mixed GWMA-CUSUM $S^{2}$ scheme and the reverse version to monitor upwards shifts using individual observations. Both of the mixed schemes have better small shifts detection ability than many competitors, including those discussed in Ali and $\mathrm{Haq}^{42}$ and, Sheu and $\mathrm{Lu}^{41}$. More importantly, it is observed that the CUSUMGWMA $S^{2}$ scheme has a slight advantage over the corresponding GWMA-CUSUM $S^{2}$ scheme in many situations.

\section{Concluding remarks}

The GWMA scheme is an extended version of the EWMA scheme with an additional adjustment parameter. The adjustment parameter allows designing a GWMA scheme in order to optimally detect a particular shift more efficiently than its EWMA counterpart. A thorough review of 61 publications on the GWMA and GWMA-related (i.e. DGWMA, Shewhart-GWMA, GWMA-CUSUM and CUSUM-GWMA) schemes are documented and, based on the discussion, it is observed that while the 
operation and implementation of the basic and enhanced GWMA-related schemes are slightly more complicated, they nevertheless have excellent detection ability as compared to their corresponding basic and enhanced EWMA schemes. More importantly, the GWMA-related monitoring schemes can be useful for quality practitioners in a variety of applications where the EWMA-related schemes are being currently used, as replacements. Note that, with the aid of computer programs, the complexity in implementation can be significantly simplified.

Finally, it is worth mentioning that more needs to be done to address the research gaps that exist for GWMA schemes and hence, we provide below a summary of some topics that have not yet been addressed:

1. Ali and $\mathrm{Haq}^{42}$ showed that the hybrid EWMA $S^{2}$ scheme has a better OOC performance than the corresponding GWMA $S^{2}$ scheme. Moreover, Huang et al ${ }^{24}$ observed that the GWMA $\bar{X}$ scheme based on repetitive sampling outperforms the hybrid EWMA $\bar{X}$ scheme based on SRS; the hybrid approach needs to be added to the basic GWMA model to monitor location, variability and joint location and variability.

2. For comparison purpose with the nonparametric GWMA schemes with unknown median parameter (i.e. Exceedance and Wilcoxon rank-sum statistics), Chakraborty et al ${ }^{65}$, Karakani et $\mathrm{al}^{75}$ and Mabude et $\mathrm{al}^{66}$ partially considered the GWMA $\bar{X}$ scheme in Case U, more thorough investigations are required. Hence a stand-alone paper on the latter is required addressing a variety of issues; for instance, (i) the effect of Phase I sample size on the performance of the Phase II scheme, (ii) the extent of the negative effect of estimating parameters as compared to when they are assumed known, etc.

3. As observed in Table 2, no nonparametric GWMA scheme research exists to monitor either the scale or the joint location and scale parameter(s); hence more needs to be done to address this gap. Readers are referred to the special issue on nonparametric schemes, edited by Chakraborti et $\mathrm{al}^{80}$ and the recent chapter contributed book on nonparametric schemes, edited by Koutras and Triantafyllou ${ }^{81}$.

4. While the EWMA scheme has been studied in the case of structured sampling techniques; e.g. ranked set sampling (RSS), double RSS, etc. Moreover, adaptive EWMA schemes also exist in SPM literature (i.e. variable sample size (VSS), variable sample interval (VSI), variable sampling size and interval (VSSI)). Note though, no research work has been done in the case of GWMA scheme combined with these enhancements.

5. A variety of parametric and nonparametric synthetic EWMA schemes for unstructured and structured sampling techniques has been reported in the literature; see for example, Haq et al ${ }^{82}$ and $\mathrm{Haq}^{83}$. The latter schemes yield better OOC detection ability than their non-integrated schemes. An investigation towards the effect of using parametric and nonparametric synthetic 
EWMA schemes to monitor a variety of quality characteristics using RSS, double RSS, etc., are recommended.

6. Measurement errors are very common in SPM application and have been shown to yield a negative effect on the performance of any monitoring scheme. Moreover, auxiliary-informationbased (AIB) estimators for the process mean have also been shown to yield a better OOC performance. Note though, so far in the SPM literature, there is no work addressing measurement errors or AIB.

7. For joint monitoring of the process mean and variability, there are many test statistics used (i.e. Max, Semi-circle, Sum of squares, separate charting statistics, etc.). However, in the literature there is no clear indication of which of these statistics has the best OOC performance as compared to all other GWMA schemes; hence, this and other similar questions in the GWMA literature need to be addressed.

8. As discussed in Sheu and $\mathrm{Lin}^{9}$, Sheu and Yang ${ }^{29}, \mathrm{Lu}^{61}$, Chakraborty et al ${ }^{30,65}$, Karakani et al ${ }^{75}$, it is very difficult to evaluate the Markov chain or exact formulas of the run-length distribution for the GWMA-related schemes; hence, more thorough researches are seriously needed to simplify the evaluation of the run-length properties using either the exact formulas or Markov chain methodologies. As a starting point see for instance Phengsalae et $\mathrm{al}^{33}$, Areepong and Sukparungsee $^{37}$ and Sukparungsee ${ }^{35}$. Moreover, R programs or any other commercial / open source statistical software for any general charting statistic need to be made readily available so that more research can be fast-tracked for GWMA-related monitoring schemes.

9. Effort needs to be paid to demonstrating how to monitor real-life datasets using the different GWMA-related schemes discussed herein. One other way, this can be done by programming the GWMA model and its enhancements into some of the well-known software programs to monitor quality characteristics in real-time.

10. Only a few attribute GWMA monitoring schemes have been proposed. More investigations on attribute GWMA schemes specifically based on fraction nonconforming (GWMA $p$ scheme), number of nonconformities (GWMA $n p$ scheme) as well as high-yield processes are needed.

11. There is no study on the economic and economic-statistical designs of the GWMA monitoring schemes that has been done in the literature so far. Therefore, researchers are encouraged to investigate these topics under both i.i.d. and correlated observations as well as for Case U.

12. Only one publication on multivariate schemes is available in the literature. Given the relevance of multivariate schemes in real-life applications, there is a lot of research works on GWMA schemes that need to be done based on parametric and nonparametric settings. 


\section{Appendix}

\section{Appendix A: Design parameters and weight structure of the GWMA scheme}

The EWMA scheme has two design parameters, i.e. $0<\lambda \leq 1$ and $L_{E}>0$; the corresponding extension to the GWMA monitoring scheme has three parameters, i.e. $0<q_{1} \leq 1, L_{G}>0$ and $\alpha_{1}>0$, with $q_{1}=1-\lambda$ and $L_{G}$ is not necessarily equal to $L_{E}$. Moreover, the $L_{G}$ coefficient is used to fix the predefined nominal IC $A R L$ value, $q_{1}$ is the smoothing parameter and $\alpha_{1}$ is an additional adjustment parameter. Note that the supplemental adjustment parameter $\alpha_{1}$ introduces more flexibility in the GWMA model as it adjust the kurtosis of the weighting function to ensure that it has an advantage over the EWMA monitoring scheme. The manner that observations are weighted within the Shewhart, CUSUM, EWMA and GWMA charting statistics is illustrated graphically in Figure A1; see similar illustration in Sheu and $\mathrm{Lin}^{9}$, Cheng et $\mathrm{al}^{20}$ and Hsu et $\mathrm{al}^{21}$. The Shewhart schemes are memoryless; hence, at the $i^{\text {th }}$ sampling point, the weight used to compute the charting statistic is equal to 1 for the $i^{\text {th }}$ observation and zero for all the previous ones. However, the CUSUM scheme uses equal weights for all previous observations. The weight structure of the observations for the EWMA and GWMA schemes are similar, i.e., geometrically decreasing; however, the weights structure or weight function kurtosis used by the GWMA scheme differs from that EWMA scheme due to the additional adjustment parameter. Note though, the EWMA weight function is a special case of the GWMA one, i.e. when $\alpha_{1}=1$.

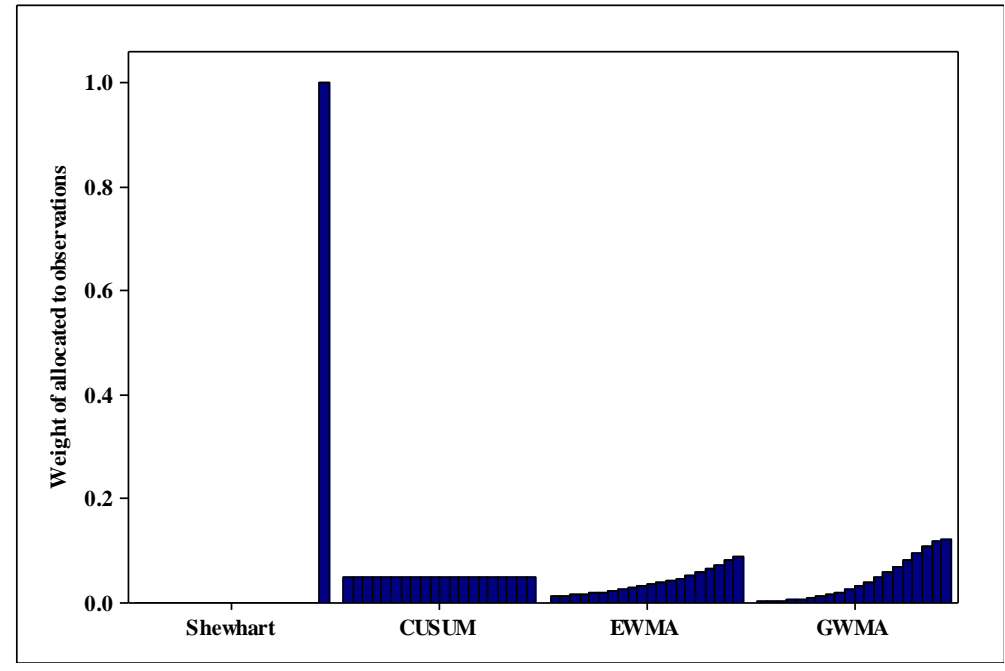

Figure A1: Observations weighting within the Shewhart, CUSUM, EWMA and GWMA charting statistics

In illustrating how the weights and charting statistics are determined for the GWMA procedure, Sheu and $\mathrm{Lin}^{9}$ proceeded as follows:

Let $p_{t}=P\left(M_{1}=t\right)$ denote the probability of the occurrence of an OOC signal at some sampling point $t$ for the first time, or since the last occurrence of the OOC signal; where the random variable $M_{1}$ denotes the number of samples until an OOC signal, with $t \in$ $\{0,1,2,3, \ldots\}$. Moreover, let $\bar{p}_{t}=P\left(M_{1}>t\right)$ be the probability that the OOC signal does not 
occur in the first $t$ samples. With the latter, it follows that $P\left(M_{1}=t\right)=\bar{p}_{t-1}-\bar{p}_{t}$. In essence, the sequence of values $\left\{P\left(M_{1}=t\right)\right\}$ are regarded as weights in the weighted moving average with $P\left(M_{1}=1\right)$ represents the weight value for the current sample, $P\left(M_{1}=2\right)$ is the weight value for the previous sample, and so on; and $P\left(M_{1}>t\right)$ is the weight value for the target value of the process mean, denoted as $\mu_{0}$. The most weight is generally given to the current sample and the weights decrease geometrically with the age of the sample.

Next, Sheu and $\operatorname{Lin}^{9}$ denoted each weight function as $\bar{p}_{t}=q_{1}^{t^{\alpha_{1}}}$ and it follows that, $P\left(M_{1}=t\right)=$ $q_{1}^{(t-1)^{\alpha_{1}}}-q_{1}^{t^{\alpha_{1}}}$. Therefore, the summation of the weight function is as follows,

$$
\begin{aligned}
\sum_{m=1}^{\infty} P\left(M_{1}=m\right) & =P\left(M_{1}=1\right)+P\left(M_{1}=2\right)+\cdots+P\left(M_{1}=t\right)+P\left(M_{1}>t\right) \\
& =\left(q_{1}^{0^{\alpha_{1}}}-q_{1}^{1^{\alpha_{1}}}\right)+\left(q_{1}^{1^{\alpha_{1}}}-q_{1}^{2^{\alpha_{1}}}\right)+\cdots+\left(q_{1}^{(t-1)^{\alpha_{1}}}-q_{1}^{t^{\alpha_{1}}}\right)+q_{1}^{t^{\alpha_{1}}} \\
& =1 .
\end{aligned}
$$

Figures A2 and A3 provide graphical illustrations of the following weight functions: $\bar{p}_{t}=q_{1}^{t^{\alpha_{1}}}$ (marginal weight function) and $P\left(M_{1}=t\right)=q_{1}^{(t-1)^{\alpha_{1}}}-q_{1}^{t^{\alpha_{1}}}$ (weights allocated to observations), with $q_{1} \in\{0.25,0.5,0.75,0.95\}$ and $\alpha_{1} \in\{0.25,0.75,1,1.25,1.75\}$. Hence, for different values of $q_{1}$, it is observed that when $\alpha_{1}>1$, the influence of recent samples is higher and the weight structure decreases at a faster rate as compared to that of $\alpha_{1}=1$. However, when $\alpha_{1}<1$, the influence of recent samples is not as pronounced as the latter case, and the weight structure decreases at a slower rate as compared to that of $\alpha_{1}=1$. 


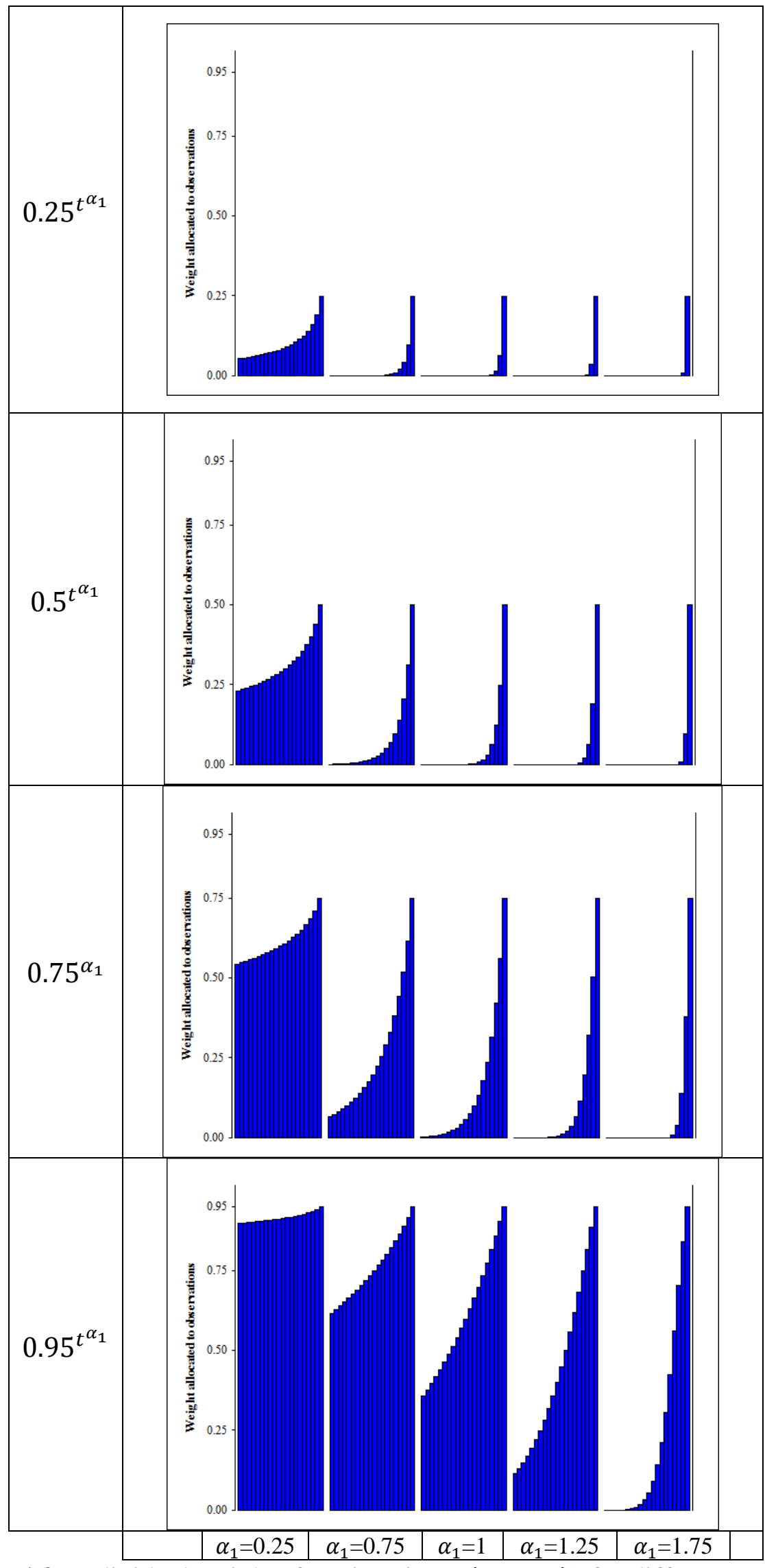

Figure A2: Individual weights function (i.e. $P\left(M_{1}=t\right)$ ) for different values of $q_{1} \in\{0.25,0.5,0.75,0.95\}$ and $\alpha_{1} \in\{0.25,0.75,1,1.25,1.75\}$ 


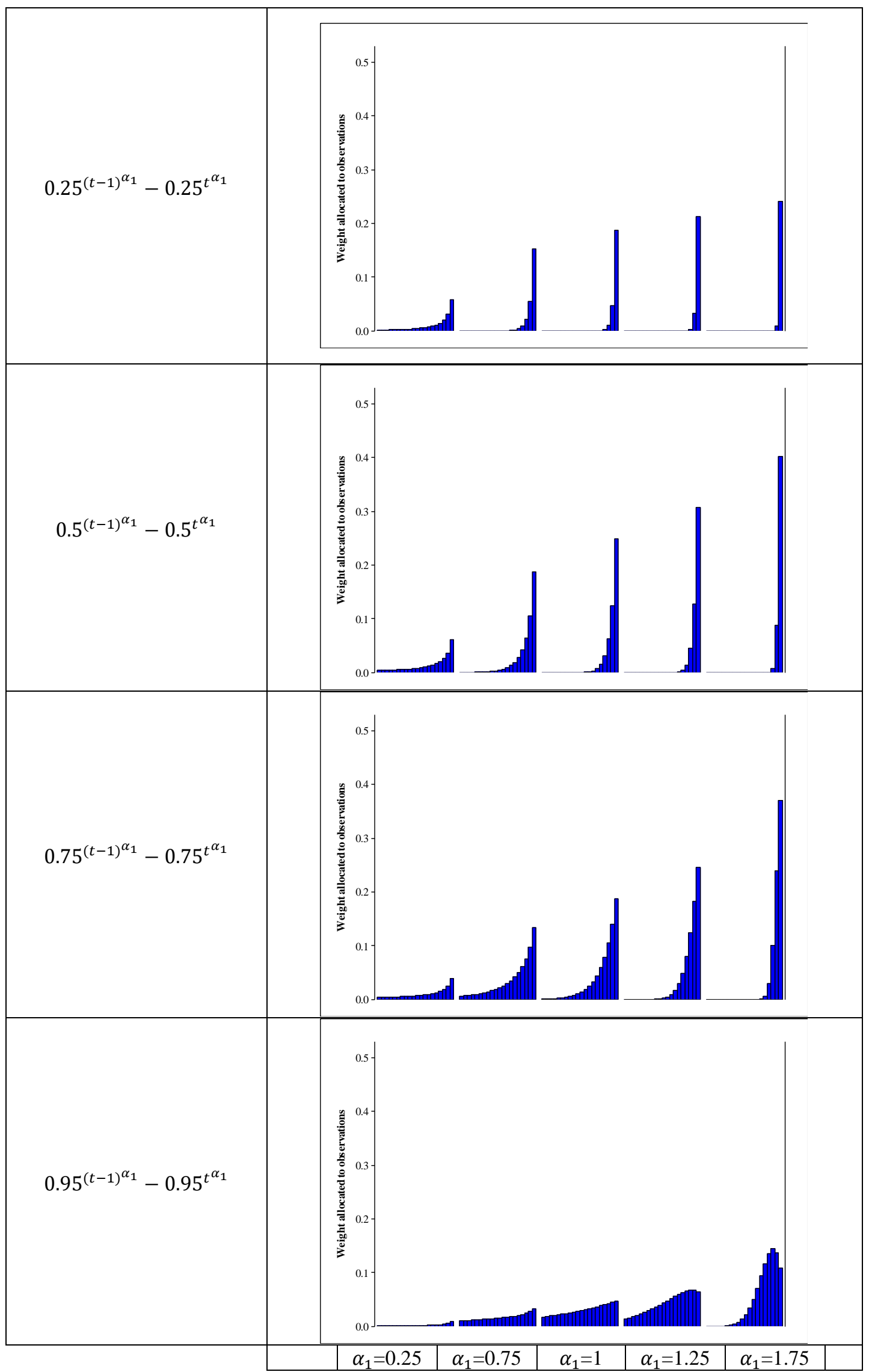

Figure A3: Weights assigned to observations for different values of $q_{1} \in\{0.25,0.5,0.75,0.95\}$ and $\alpha_{1} \in\{0.25,0.75,1,1.25,1.75\}$ 


\section{Appendix B: Run-length properties of the GWMA-related schemes}

The number of charting statistics to be plotted on a monitoring scheme before an OOC signal is observed is called the run-length $(R L)$. Numerous $R L$ properties have been used to evaluate the performance of GWMA-related schemes; these are the average run-length $(A R L)$, the standard deviation of the run-length (SDRL) and some percentile run-length $(P R L)$ such as the median, $5^{\text {th }}, 25^{\text {th }}$, $75^{\text {th }}, 95^{\text {th }}$ percentiles. So far in the SPM literature, Monte Carlo simulations have been the most used method to compute the $R L$ distribution of the GWMA schemes; with no publications yet using the exact formulas. This is because the theoretical expressions that are required to be evaluated are very complex; see for instance Chakraborty et $\mathrm{al}^{30,65}$ and Karakani et $\mathrm{al}^{75}$. Note that Phengsalae et $\mathrm{al}^{33}$, Areepong and Sukparungsee ${ }^{37}$ and Sukparungsee ${ }^{35}$ used the Markov chain approach to evaluate the run-length properties of the GWMA schemes and observed that they are closer in magnitude to those that are obtained via simulation; however, simulation approach takes longer as compared to Markov chain in terms of computer processing unit (CPU) computational time. The popularity of the Monte Carlo simulations stems from the fact that no matter how complicated the $R L$ distribution, it can easily and accurately be calculated with computer simulations, provided that the number of simulation runs is large enough.

Next, the computation of the IC and OOC $R L$ properties for the GWMA $\bar{X}$ scheme in the case of a standard normal distribution using $r$ simulation runs are described. The computation is done in two stages. In the first stage, a search for the design parameter(s) that gives an attained IC $A R L$ as close as possible to the nominal $A R L_{0}$ is conducted. If such design parameters exist, they are called the optimal design parameters. In the second stage, these optimal design parameters are used to compute OOC $A R L$ values. Hence, when the parameters of the distribution are known or have already been estimated from Phase I, the $R L$ properties of the GWMA $\bar{X}$ schemes can be computed using the following Monte Carlo algorithm:

\section{Stage 1 - Search of the optimal design parameter $L_{G}$ :}

1. Specify the nominal $A R L_{0}, n, r, q_{1}$ and $\alpha_{1}$.

2. (a) Fix a first value of $L_{G}$ and calculate the control limits and go to Step 3.

(b) If required, increase (or decrease) $L_{G}$ and recalculate the control limits so that the attained IC $A R L$ get closer to the nominal $A R L_{0}$.

3. Randomly generate a sample from the $N(0,1)$ distribution. Calculate the charting statistic and compare it to the control limits found in Step 2. If the charting statistic plots between the control limits, then collect the next subgroup and calculate its charting statistic and compare it to the control limits. Continue this process until a sample point plots beyond the control limits. Then record the number of subgroups plotted until an OOC signal occurs, this represents one value of the IC $R L\left(R L_{0}\right)$ distribution. Repeat Step 3 a total of $r$ times to find the $(r \times 1) R L_{0}$ vector. 
4. Once the $R L_{0}$ vector is obtained, calculate the attained IC $A R L\left(=\frac{1}{r} \sum_{i=1}^{r} R L_{0_{i}}\right)$. If the attained IC $A R L$ is equal or much closer to the nominal $A R L_{0}$, go to Step 5. Otherwise, go back to Step 2(b) (i.e., since the attained IC $A R L$ is considerably greater (smaller) than the nominal value, then update the control limit(s) narrower (wider) and repeat again Steps 3 and 4).

5. The design parameter $L_{G}$ found in Step 4 is called the optimal design parameter. Record the optimal $L_{G}$ and its corresponding control limits. Thus, the search of the optimal $L_{G}$ is completed.

\section{Stage 2 - Computation of the characteristics of the OOC $R L\left(R L_{1}\right)$ :}

6. For a specific shift $\delta(\delta \neq 0)$, randomly generate a test sample from the $N(\delta, 1)$ distribution. Calculate the charting statistic(s) and compare to the control limit(s) found in Step 5. If the charting statistic plots between the control limits, then collect the next subgroup and calculate its charting statistic and compare it to the control limits. Continue this process until a sample point plots beyond the control limits. Then record the number of subgroups plotted until an OOC signal occurs. This number represents one value of the $R L_{1}$ distribution. Repeat Step 6 a total of $r$ times to find the $(r \times 1) R L_{1}$ vector.

7. Once the $R L_{1}$ vector is obtained, calculate the OOC $A R L$ value $\left(=\frac{1}{r} \sum_{i=1}^{r} R L_{1_{i}}\right)$.

8. The computation of the characteristics of the $R L_{1}$ is completed.

Note that: (i) in Steps 4 and 7, other characteristics of the $R L$ such as the $S D R L$, the $5^{\text {th }}, 25^{\text {th }}, 50^{\text {th }}, 75^{\text {th }}$ and $95^{\text {th }} P R L$ can also be computed; (ii) the extension for other statistics (median, variance, range, etc.) and other distributions can be done in a similar way by modifying the distribution and the charting statistic computed in Steps 3 and 6, accordingly.

\section{References}

1. Woodall WH. Control charts based on attributes data: bibliography and review. Journal of Quality Technology, 1997;29(2):172-183.

2. Chakraborti S, Graham MA. Nonparametric (Distribution-free) control charts: An updated overview and some results. Quality Engineering, 2019;31(4):523-544.

3. Jones-Farmer LA, Woodall WH, Steiner SH, Champ CW. An overview of phase I analysis for process improvement and monitoring. Journal of Quality Technology 2014;46(3):265-280.

4. Psarakis S. Adaptive control charts: Recent developments and extensions. Quality and Reliability Engineering International, 2015;31(7):1265-1280.

5. Maleki MR, Amiri A, Castagliola P. An overview on recent profile monitoring papers (20082018) based on conceptual classification scheme. Computers \& Industrial Engineering, 2018;126:705-728.

6. Sheu S-H, Griffith W-S. Optimal number of minimal repairs before replacement of a system subject to shocks. Naval Research Logistics, 1996;43(3):319-333.

7. Sheu S-H. A generalized age and block replacement of a system subject to shocks. European Journal of Operational Research, 1998;108(2):345-362.

8. Sheu S-H. Extended optimal replacement model for deteriorating systems. European Journal of Operational Research, 1999;112(3):503-516.

9. Sheu S-H, Lin T-C. The generally weighted moving average control chart for detecting small shifts in the process mean, Quality Engineering, 2003;16(2):209-231. 
10. Shamma SE, Shamma AK. Development and evaluation of control charts using double exponentially weighted moving averages. The International Journal of Quality and Reliability Management, 1992;9(6):18-26.

11. Lucas JM. Combined Shewhart-CUSUM quality control schemes. Journal of Quality Technology, 1982;14(2):51-59.

12. Lucas JM, Saccucci MS. Exponentially weighted moving average control schemes. Technometrics, 1990;32(1):1-12.

13. Abbas N, Riaz M, Does RJMM. Mixed exponentially weighted moving average-cumulative sum charts for process monitoring. Quality and Reliability Engineering International, 2013;29(3):345356.

14. Zaman B, Riaz M, Abbas N, Does RJMM. Mixed cumulative sum-exponentially weighted moving average control charts: an efficient way of monitoring process location. Quality and Reliability Engineering International, 2015;31(8):1407-1421.

15. Lin T-C. Composite Shewhart-Poisson GWMA control chart with sensitizing rules. $8^{\text {th }}$ International Conference on Intelligent Systems Design and Application, 2008; DOI: 10.1109/ISDA.2008.328.

16. Lu S-L. Novel design of composite generally weighted moving average and cumulative sum charts. Quality and Reliability Engineering International, 2017;33(8):2397-2408.

17. Ali R, Haq A. A mixed GWMA-CUSUM control chart for monitoring the process mean. Communications in Statistics - Theory Methods, 2018;47(15):3779-3801.

18. Jensen WA, Jones-Farmer LA, Champ CW, Woodall WH. Effects of parameter estimation on control chart properties: A literature review. Journal of Quality Technology, 2006;38(4):349-364.

19. Psarakis S, Vyniou A, Castagliola P. Some recent developments on the effects of parameter estimation on control charts. Quality and Reliability Engineering International, 2013;30(8):11131129.

20. Cheng S-R, Yeh Y-H, Shu M-H. A comparative study of the monitoring performance for weighted control charts. $2^{\text {nd }}$ International Conference on Innovative Computing, Information and Control, 2007; DOI:10.1109/icicic.2007.8.

21. Hsu B-M, Lai P-J, Shu M-H, Hung Y-Y. A comparative study of the monitoring performance for weighted control charts. Journal of Statistics and Management Systems, 2009;12(2):207-228.

22. Chiu W-C. Generally weighted moving average control charts with fast initial response features. Journal of Applied Statistics, 2009;36(3):255-275.

23. Haq A, Abidin ZU. An enhanced GWMA chart for process mean. Communications in Statistics Theory and Methods, 2020;49(4):847-866.

24. Huang C-J, Chen J-H, Lu S-L. Generally weighted moving average control charts using repetitive sampling. Communications in Statistics - Theory and Methods, 2020; DOI: 10.1080/03610926.2019.1634212.

25. Aslam M, Al-Marshadi AH, Jun C-H. Monitoring process mean using generally weighted moving average chart for exponentially distributed characteristics. Communications in Statistics Simulation and Computation, 2017;46(5):3712-3722.

26. Yang L, Sheu S-H. Integrating multivariate engineering process control and multivariate statistical process control. The International Journal of Advanced Manufacturing Technology, 2006;29(1-4):129-136.

27. Sheu S-H, Lu S-L. Monitoring the mean of autocorrelated observations with one generally weighted moving average control chart. Journal of Statistical Computation and Simulation, 2009;79(12):1393-1406.

28. Lu S-L. Applying fast initial response features on GWMA control charts for monitoring autocorrelation data. Communications in Statistics - Theory and Methods, 2016;45(11):33443356.

29. Sheu S-H and Yang L. The generally weighted moving average control chart for monitoring the process median. Quality Engineering, 2006;18(3):333-344.

30. Chakraborty N, Human SW, Balakrishnan N. A generally weighted moving average chart for time between events. Communications in Statistics - Simulation and Computation, 2017;46(10):77907817. 
31. Sheu S-H, Chiu W-C. Poisson GWMA control chart. Communications in Statistics - Simulation and Computation, 2007;36(5):1099-1114.

32. Brooks D, Evans DA. An approach to the probability distribution of CUSUM run length. Biometrika, 1972;59(3):539-549.

33. Phengsalae Y, Areepong Y, Sukparungsee S. An approximation of ARL of Poisson GWMA using Markov chain approach. Thailand Statistician, 2015;13(1):111-124.

34. Chiu W-C, Sheu S-H. Fast initial response features for Poisson GWMA control charts. Communications in Statistics - Simulation and Computation, 2008;37(7):1422-1439.

35. Sukparungsee S. An approximation of average run length using the Markov chain of a generally weighted moving average chart to monitor the number of defects. Songklanakarin Journal of Science and Technology, 2018;40(6):1368-1377.

36. Alevizakos V, Koukouvinos C. A generally weighted moving average control chart for zeroinflated Poisson processes. Quality and Reliability Engineering International, 2020;36(2):675704.

37. Areepong Y, Sukparungsee S. Approximation average run length of zero-inflated binomial GWMA chart with Markov chain approach. Far East Journal of Mathematical Sciences, 2016;99(3):413-428.

38. Kang HW, Kang CW, Baik JW, Nam SH. Demerit-GWMA Control Chart for Demerit Statistics. Advanced Materials Research, 2011;156-157:413-421.

39. Kang HW, Baik JW, Choi YJ, Nam SH. Demerit-GWMA Control Chart with Fast Initial Response. Applied Mechanics and Materials, 2012;156:1655-1660.

40. Sheu S-H, Tai S-H. Generally weighted moving average control chart for monitoring process variability. The International Journal of Advanced Manufacturing Technology, 2006;30(1-4):452458.

41. Sheu S-H, Lu S-L. The generally weighted moving average variance chart. Communications in Statistics - Theory and Methods, 2013;42(17):3204-3214.

42. Ali R, Haq A. New memory-type dispersion control charts. Quality and Reliability Engineering International, 2017;33(8):2131-2149.

43. Huwang L, Huang C-J, Wang YHT. New EWMA control charts for monitoring process dispersion. Computational Statistics \& Data Analysis, 2010;54(10):2328-2342.

44. Sheu S-H, Tai S-H, Hsieh Y-T, Lin T-C. Monitoring process mean and variability with generally weighted moving average control charts. Computers \& Industrial Engineering, 2009;57:401-407.

45. Sheu S-H, Lu S-L. Monitoring small shifts in the autocorrelated process mean and variance with GWMA charts based on residuals. Asia Pacific Journal of Operational Research, 2008;25(6):781-792.

46. Sheu S-H, Lu S-L. The effect of autocorrelated observations on a GWMA control chart performance. International Journal of Quality and Reliability Management, 2009;26(2):112-128.

47. Sheu S-H, Huang C-J and Hsu T-S. Extended maximum generally weighted moving average control chart for monitoring process mean and variability. Computers \& Industrial Engineering, 2012;62:216-225.

48. Teh SY, Khoo MBC, Wu Z. Monitoring process mean and variance with a single generally weighted moving average chart. Communications in Statistics - Theory and Methods, 2012;41(12):2221-2241.

49. Nguyen T-L, Shu M-H, Hsu B-M. Monitoring the coating thickness of pharmaceutical tablets with MaxGWMA control chart. Applied Mechanics and Materials, 2013;372:325-330. DOI:10.4028/www.scientific.net/amm.372.325.

50. Hsu B-M, Nguyen T-L, Shu M-H, Huang Y-F. Using MaxGWMA control chart to monitor the quality of TFT-LCD. International Conference on Computational Science and Its Applications, 2013;380-390. DOI:10.1007/978-3-642-39640-3_28.

51. Teh SY, Khoo MBC. A study on the effect of skewed distribution on the performances of MaxEWMA and Max-GWMA charts. Risk and Decision Analysis, 2012;3(4):255-262. DOI:10.3233/RDA-2012-0068. 
52. Phanyaem S. An evaluation of average run length of Max-EWMA and Max-GWMA charts. International Journal of Mathematical, Computational, Physical and Quantum Engineering, 2013;8:777-780.

53. Petcharat K. A sensitive of maximum generally weighted moving average control chart for AR(p) processes. Proceedings of the International MultiConference of Engineers and Computer Scientists, 2018; Vol I.

54. Sheu S-H, Huang C-J, Hsu T-S. Maximum chi-square generally weighted moving average control chart for monitoring process mean and variability. Communications in Statistics - Theory and Methods, 2013;42(23):4323-4341.

55. Huang C-J. A sum of squares generally weighted moving average control chart. Communications in Statistics - Theory and Methods, 2014;43(23):5052-5071.

56. Huang C-J. A new GWMA control chart for monitoring process mean and variability. Communications in Statistics - Theory and Methods, 2015;44(18):3841-3856.

57. Mohsin M, Aslam M, Jun C-H. A new generally weighted moving average control chart based on Taguchi's loss function to monitor process mean and dispersion. Journal of Engineering Manufacture, 2016;230(8):1537-1547.

58. Arif $\mathrm{OH}$, Aslam M. A new generalized range control chart for the Weibull distribution. Complexity, 2018; Article ID:9453589, 8pages.

59. Hong EP, Kang HW, Kang CW, Baik JW. CV control chart using GWMA technique. Advanced Materials Research, 2011;337:247-254.

60. Hong EP, Kang CW, Kang HW. Extension of CV-GWMA control chart with fast initial response feature. Journal of Computational and Theoretical Nanoscience, 2012;14(1):471-476.

61. Lu S-L. An extended nonparametric exponentially weighted moving average sign control chart, Quality and Reliability Engineering International, 2015;31(1):3-13.

62. Chen J-H, Lu S-L, Sheu S-H. A nonparametric generally weighted moving average sign chart based on repetitive sampling. Communications in Statistics - Simulation and Computation, 2020; DOI: 10.1080/03610918.2019.1664574.

63. Chakraborty N, Chakraborti S, Human SW, Balakrishnan N. A generally weighted moving average signed rank control chart. Quality and Reliability Engineering International, 2016;32(8):2835-2845.

64. Sukparungsee S. Robustness of the generally weighted moving average signed-rank control chart for monitoring a shift of skew processes. Matter: International Journal of Science and Technology, 2018;4(3):125-137.

65. Chakraborty N, Human SW, Balakrishnan N. A generally weighted moving average exceedance chart. Journal of Statistical Computation and Simulation, 2018;88(9):1759-1781.

66. Mabude K, Malela-Majika J-C, Shongwe SC. A new distribution-free generally weighted moving average monitoring scheme for detecting unknown mean shifts, International Journal of Industrial Engineering Computations, 2020;11(2):235-254.

67. Sheu S-H, Hsieh Y-T. The extended GWMA control chart. Journal of Applied Statistics, 2009;36(2):135-147.

68. Alevizakos V, Koukouvinos C, Lappa A. Monitoring of time between events with a double generally weighted moving average control chart. Quality and Reliability Engineering International, 2019;35(2):685-710.

69. Chiu W-C, Lu S-L. On the steady-state performance of the Poisson double GWMA control chart. Quality Technology \& Quantitative Management, 2015;12(2):195-208.

70. Kang HW, Baik JW. Double generally weighted moving average control chart for demerit statistics. Advanced Science Letters, 2012;13(1):183-188.

71. Tai S-H, Hsieh Y-T, Huang C-J. The combined double generally weighted moving average control chart for individual observations. International Conference on Management and Service Science, 2010:1-4. DOI:10.1109/icmss.2010.5576113.

72. Huang C-J, Tai S-H, Lu S-L. Measuring the performance improvement of a double generally weighted moving average control chart. Expert Systems with Applications, 2014;41(7):3313-3322.

73. Lu S-L. Nonparametric double generally weighted moving average sign charts based on process proportion. Communications in Statistics - Theory and Methods, 2018;47(11):2684-2700. 
74. Phanyaem S. Generally weighted moving average sign control chart using repetitive sampling. Proceedings of the International MultiConference of Engineers and Computer Scientists, 2018; Vol I.

75. Karakani HM, Human SW, Van Niekerk J. A double generally weighted moving average exceedance control chart. Quality and Reliability Engineering International, 2019;35(1):224-245.

76. Nelson LS. The Shewhart control chart tests for special causes. Journal of Quality Technology, 1984;16(4):237-239.

77. Tai S-H, Lin T-C, Chen Y. Design and implementation of the extended exponentially weighted moving average control charts, In Proceedings of the International Conference on Management and Service Science, IEEE Xplore, 2009;1-4.

78. Ali R, Haq A. New GWMA-CUSUM control chart for monitoring the process dispersion. Quality and Reliability Engineering International, 2018;34(6):997-1028.

79. Huang C-J, Lu S-L, Chen J-H. Enhanced generally weighted moving average variance charts for monitoring process variance with individual observations. Quality and Reliability Engineering International, 2020;36(1):285-302.

80. Chakraborti S, Qiu P, Mukherjee A (eds). Special issue: Nonparametric statistical process control charts. Quality and Reliability Engineering International, 2015;31(1):1-151.

81. Koutras MV, Triantafyllou IS. Distribution-free methods for statistical process monitoring and control. Switzerland: Springer. 2020; DOI: 10.1007/978-3-030-25081-2.

82. Haq A, Brown J, Moltchanova E. New synthetic EWMA and synthetic CUSUM control charts for monitoring process mean. Quality and Reliability Engineering International, 2016;32(1):269-290.

83. Haq A. A new nonparametric synthetic EWMA control chart for monitoring process mean. Communications in Statistics - Simulation and Computation, 2019;48(6):1665-1676. 